\title{
Knowledge, attitudes and practices of health professionals in public health institutions on emergency contraception in Pietermaritzburg, KwaZulu-Natal Province, South Africa
}

\author{
E Sibanda, MB ChB, Dip Fam Med, Dip Obst, FCOG (SA); M J Titus, MB ChB, FCOG (SA), LLM, PG Dip Intl Res Ethics \\ Department of Obstetrics and Gynaecology, Nelson R Mandela School of Medicine, University of KwaZulu-Natal, Durban, South Africa
}

Corresponding author: E Sibanda (emanuelsibanda@yahoo.com)

\begin{abstract}
Background. Although emergency contraception (EC) is widely available, its use is surrounded by many controversies. Overall, it seems to be underutilised worldwide.

Objectives. To determine healthcare professionals' knowledge, attitudes and perceptions regarding EC, and how frequently they encounter, educate and issue it to patients.

Methods. A questionnaire-based survey of doctors and nurses (volunteers) working in obstetrics and gynaecology was conducted in 3 public hospitals and 17 clinics in Pietermaritzburg, KwaZulu-Natal Province, South Africa. Data were analysed using SPSS.

Results. Sixty-seven (25\%) doctors and 201 (75\%) nurses participated in the survey. Awareness of the three ECs available in the public sector overall was $56.4 \%$, and $62.7 \%$ of participants could prescribe one EC correctly. Only $39.6 \%$ knew that EC pills prevent ovulation. Seventy-six percent thought that the use of EC could lead to high-risk sexual behaviour, high risk of transmission of HIV and non-use of other forms of contraception. Only 7.8\% saw patients seeking EC often, 5.6\% issued it often and 23.5\% educated patients about it often. Conclusion. Participants were familiar with EC, but lacked accurate and detailed knowledge about its mechanism of action and had misperceptions on its social impact. They seldom prescribed it.
\end{abstract}

S Afr J Obstet Gynaecol 2017;23(1):7-11. DOI: 10.7196/SAJOG.2017.v23i1.1091

It is estimated that about $41.0 \%$ of the 208 million pregnancies that occurred worldwide in 2008 were unintended. ${ }^{[1]}$ East and Central Africa have the highest rates of unintended pregnancies and about 14 million unintended pregnancies are estimated to occur in subSaharan Africa annually. ${ }^{[1,2]}$ Unintended pregnancies are resolved differently by women. Globally, there were an estimated 42 million induced abortions in 2003, of which $48 \%$ were unsafe and $97 \%$ of the unsafe abortions were performed in developing countries. ${ }^{[3]}$ The World Health Organization (WHO) estimated that 21.6 million unsafe abortions occurred worldwide in 2008, an increase from 19.7 million in 2003, ${ }^{[4]}$ with Eastern and Central Africa having the highest rates. ${ }^{[5]}$ Unsafe abortions have a negative impact on maternal morbidity and mortality. A reduction in unintended pregnancies may result in a reduction of unsafe abortions, hence lowering maternal mortality.

In situations where there is unprotected sexual intercourse or contraceptive method failure, emergency contraception (EC) may be used to prevent unintended pregnancies. Although EC is widely available in many countries, its use has been marred with controversies and misperceptions, especially concerning its mode of action, impact on behaviour and safety. EC pills prevent pregnancy by inhibiting or delaying ovulation, but they cannot disrupt an established pregnancy. However, an analysis of 1077 articles in 113 newspapers between 1992 and 2002 showed that $44.5 \%$ of them included at least one instance of confusion between EC and medical abortion, with $31.0 \%$ of the articles inaccurately portraying the mode of action of EC as medical abortion. ${ }^{[6]}$ The use of EC varies in different countries, and overall it is underutilised worldwide. In a cross-sectional survey of 600 pregnant teenagers requesting termination of pregnancy in China, $47.7 \%$ had heard of EC and among them, $44.0 \%$ had used it a least once within the 6 months before the pregnancy. ${ }^{[7]}$ In a survey of college students in Pennsylvania, USA, $74.0 \%$ had heard of EC. ${ }^{[8]}$ In Turkey, a survey of married women showed that $39.6 \%$ knew about EC. ${ }^{[9]}$ A study conducted in South Africa (SA) in 2001 showed that only $22.8 \%$ of patients interviewed at public primary healthcare facilities had heard about EC ${ }^{[10]}$ A survey of tertiary students in Durban, SA, showed that $56.5 \%$ of them had heard of EC, ${ }^{[11]}$ and a Kenyan study showed that only $11.0 \%$ of family planning patients surveyed had heard of EC. ${ }^{[12]}$

Lack of knowledge and misperceptions about EC also exists among healthcare professionals, therefore hindering the dissemination of knowledge to patients. One such example is a Florida survey, which revealed that $56 \%$ of pharmacists thought EC caused birth defects and $46 \%$ thought it caused abortion. ${ }^{[13]}$ A national survey of obstetricians and gynaecologists in the USA between October 2008 and January 2009 showed that gender, religion and divergent beliefs about EC influenced their practices. ${ }^{[14]}$ In SA, the public sector is the main provider of contraceptives. $\mathrm{EC}$ is available in the form of the combined oral contraceptive (COC) pill, the copper intra-uterine contraceptive device (Cu-IUCD) and progesterone-only pills (POPs). However, promotion of EC seems to be low. Healthcare professionals have a responsibility to counsel and offer their patients knowledge on all forms of contraception, including EC.

This study therefore aimed to establish the knowledge and attitudes of healthcare professionals (doctors and nurses) towards issuing EC in the Pietermaritzburg area of KwaZulu-Natal Province, SA. 
Furthermore, it aimed to establish if the healthcare workers might be a contributory factor in the lack of knowledge on EC in the public sector. Promotion of EC by healthcare professionals would have a positive impact on its use, which would decrease unintended pregnancies.

\section{Methods}

A purposive sample of doctors and nurses working in the three public hospitals in the obstetrics and gynaecology units, and 17 selected public clinics in Pietermaritzburg, SA, rendering antenatal, postnatal and contraceptive services, participated in the study in January 2013. All the selected facilities provided primary healthcare and family planning services except the tertiary hospital, which only provided a family planning service.

Participation in the study was voluntary and only those who completed the questionnaire were included. The healthcare professionals included in the study were specialist obstetricians and gynaecologists, registrars, medical officers, medical interns, midwives, registered nurses and enrolled nurses.

Those who participated were given a 25-item questionnaire containing closed- and open-ended questions. In 22 of the questions on the questionnaire, the participants were given choices from which they could choose the correct answer. The questionnaire was completed anonymously for 20 - 30 minutes under the supervision of the researcher and the forms were collected immediately after completion.

To assess their knowledge, participants were asked to mention the ECs they were aware of, how they were prescribed, the time limit within which specific ECs should be taken and their effectiveness. They were also asked questions about ECs' indications, mechanisms of action, teratogenicity, side-effects and questions pertaining to their prescription. Attitudes towards prescription were assessed by finding out if they agreed with the use of EC and if they thought its use could lead to high-risk sexual behaviour and transmission of sexually transmitted infections (STIs). Practices were assessed by asking how frequently they encountered, taught patients and prescribed EC to them.

The answers to the questions on the questionnaire were coded. The data were then captured and subsequently analysed using the Statistical Package for Social Sciences version 21 (IBM Corp., USA). Descriptive statistics were used to summarise the results. This study was approved by the Biomedical Research Ethics and Postgraduate Committees of the University of KwaZulu-Natal (ref. no. BE269/12).

\section{Results}

Out of 355 healthcare professionals who were approached (80 doctors, 95 clinic nurses and 180 hospital nurses), 268 (75.5\%) participated and completed the questionnaires fully. Of the participants, 67 (25\%) were doctors and 201 (75\%) were nurses. All the doctors who participated in the study worked in one of the three public hospitals in Pietermaritzburg, while two-thirds of the nurses who participated worked at one of the three hospitals and one-third worked at the clinics. The mean age of the doctors was 29.1 years, with an average work experience of 3.8 years, and the mean age of nurses was 38.1 years, with an average work experience of 10.8 years. Table 1 shows the detailed demographics.

\section{Knowledge}

Most participants could name an EC method. The COC (Yuzpe) regimen was the most commonly mentioned method (82.5\%),
Table 1. Demographics of all participants $(N=268)$

\begin{tabular}{ll}
\hline & $\boldsymbol{n}(\%)^{\star}$ \\
\hline Profession & $29(10.8)$ \\
Enrolled nurse & $172(64.2)$ \\
Professional nurse & $41(15.3)$ \\
Medical intern & $11(4.1)$ \\
Medical officer (obstetrics and gynaecology) & $14(5.2)$ \\
Registrar (obstetrics and gynaecology) & $1(0.4)$ \\
Specialist (obstetrician and gynaecologist) & $268(100)$ \\
Total & \\
Work places & $67(25)$ \\
Clinic nurses & $43(16)$ \\
Hospital labour ward nurses & $41(15.3)$ \\
Hospital antenatal ward nurses & $26(9.7)$ \\
Hospital postnatal ward nurses & $10(3.7)$ \\
Hospital O\&G OPD nurses & $11(4.1)$ \\
Hospital gynaecology ward nurses & $3(1.1)$ \\
Hospital family planning nurses & $67(25)$ \\
Hospital O\&G doctors & \\
Sex & $40(14.9)$ \\
Male & $228(85.1)$ \\
Female & \\
Age distribution (years) & 35.73 \\
Mean & $20-61$ \\
Range & \\
× $\&$ = obstess otherricse and gynaecology; OPD = out-patient department. & \\
&
\end{tabular}

while ulipristal acetate was the least mentioned (0.4\%). When asked to prescribe two ECs of their choice, $62.7 \%$ of participants could prescribe their first choice and $31.2 \%$ could correctly prescribe their second choice. Their correct responses on the time limit within which an EC of their choice could be used were: $55.6 \%$ for the COC time limit of 72 hours; $53 \%$ for the 72 -hour time limit of POP (Norlevo) and $20 \%$ for the 120-hour time limit of POP (Norlevo); $16.7 \%$ for the Cu-IUCD time limit of 120 hours. The participants' responses to a question on their knowledge of the indications of EC were: $89.6 \%$ mentioned rape or sexual assault, $79.5 \%$ mentioned unprotected sex, $43.3 \%$ mentioned a burst condom and $20.1 \%$ mentioned missed pills. Concerning the issues around prescription of EC, $70.2 \%$ stated that a prescription was not needed to access EC in SA, 50.7\% stated that a repeat dose of EC should not be given within 1 month of giving another dose and $53 \%$ stated that EC should be issued to women who are $>12$ years of age (Table 2 ).

Concerning the mechanisms of action of EC pills, 39.6\% of participants selected that they prevent ovulation, $76.5 \%$ that they prevent implantation, $24.3 \%$ that they cause abortion, $64.6 \%$ that they prevent fertilisation and $8.6 \%$ that they cause malformations that are incompatible with life (Table 3). When asked about the effect of EC pills on the fetus if taken unknowingly by a woman who is already pregnant, their responses were as follows: $42.2 \%$ thought that the woman would have a spontaneous miscarriage, $35.1 \%$ thought that the fetus might have minor congenital abnormalities, 14.2\% thought that the fetus would have major congenital abnormalities and $34.0 \%$ said that there would be no effect on the baby $(9.0 \%$ of doctors and 


\begin{tabular}{|c|c|c|c|c|c|}
\hline & \multirow{2}{*}{$\begin{array}{l}\text { Doctors } \\
(N=67), \\
n(\%)\end{array}$} & \multicolumn{3}{|c|}{ Nurses, $\boldsymbol{n}(\%)$} & \multirow[b]{2}{*}{$\begin{array}{l}\text { Total } \\
(N=268), n(\%)\end{array}$} \\
\hline & & $\begin{array}{l}\text { Hospital } \\
(N=134)\end{array}$ & Clinic $(N=67)$ & Total $(N=201)$ & \\
\hline \multicolumn{6}{|l|}{ Type of EC } \\
\hline COC pill (Yuzpe) & $52(77.6)$ & $110(82.1)$ & $59(88.1)$ & $169(84.1 \%)$ & $221(82.5)$ \\
\hline POP (Norlevo) & $46(68.7)$ & $63(68.0)$ & $49(73.1)$ & $112(55.7)$ & $158(59.0)$ \\
\hline Cu-IUCD & $44(65.7)$ & $26(19.4)$ & $4(6.0)$ & $30(14.9)$ & $74(27.6)$ \\
\hline Mifepristone & $4(6.0)$ & 0 & 0 & 0 & $4(1.5)$ \\
\hline Ulipristal acetate & $1(1.5)$ & 0 & 0 & 0 & $1(0.4)$ \\
\hline \multicolumn{6}{|l|}{ Correct prescription of EC } \\
\hline Choice 1 & $39(58.2)$ & $77(57.5)$ & $52(77.6)$ & $129(64.2)$ & $168(62.7)$ \\
\hline Choice 2 & $33(49.3)$ & 29 (21.6) & $20(29.9)$ & $49(24.4)$ & $82(30.5)$ \\
\hline \multicolumn{6}{|c|}{ Time frame for administration of EC } \\
\hline COC (72 hours) & $23(34.3)$ & $49(36.5)$ & $18(26.9)$ & $67(33.3)$ & $90(33.6)$ \\
\hline POP (Norlevo) (72 hours) & $17(25.4)$ & $17(12.7)$ & $19(28.4)$ & $36(17.9)$ & $53(19.8)$ \\
\hline POP (Norlevo) (120 hours) & $3(4.5)$ & $8(6.0)$ & $9(13.4)$ & $17(8.5)$ & $20(7.5)$ \\
\hline Cu-IUCD (120 hours) & $1(1.5)$ & 0 & 0 & 0 & $1(0.4)$ \\
\hline \multicolumn{6}{|l|}{ Indications for $\mathrm{EC}$} \\
\hline Rape/sexual assault & $59(88)$ & $127(94.8)$ & $54(80.6)$ & $181(90)$ & $240(89.6)$ \\
\hline Unprotected sex & $55(82.1)$ & $100(74.6)$ & $58(86.6)$ & $158(78.6)$ & $213(79.5)$ \\
\hline Burst condom & $34(50.1)$ & $43(32.1)$ & $39(58.2)$ & $82(40.8)$ & $116(43.3)$ \\
\hline Missed pills & $7(10.4)$ & $32(23.9)$ & $15(22.4)$ & $47(23.4)$ & $54(20.1)$ \\
\hline \multicolumn{6}{|c|}{ Number of times EC pills can be used in a month } \\
\hline Once & $35(52.2)$ & $68(50.7)$ & $33(49.3)$ & $101(50.2)$ & $136(50.7)$ \\
\hline Twice & $7(10.4)$ & $7(5.2)$ & $3(4.5)$ & $10(5.0)$ & $17(6.3)$ \\
\hline Thrice & 0 & 0 & $1(1.5)$ & $1(0.5)$ & $1(0.4)$ \\
\hline Unlimited & $9(13.4)$ & $20(14.9)$ & $10(14.9)$ & $30(14.9)$ & $39(14.6)$ \\
\hline Do not know & $16(24)$ & $39(29.1)$ & $20(29.9)$ & $59(29.4)$ & $75(28)$ \\
\hline \multicolumn{6}{|c|}{ Age restriction to access EC in SA } \\
\hline$>12$ years & $30(44.8)$ & $74(55.2)$ & $38(56.7)$ & $112(55.7)$ & $142(53)$ \\
\hline$>16$ years & $3(4.5)$ & $6(4.5)$ & $3(4.5)$ & $9(4.5)$ & $12(4.5)$ \\
\hline$>18$ years & 0 & $7(5.2)$ & $1(1.5)$ & $8(4)$ & $8(3)$ \\
\hline No age restriction & $27(40.2)$ & $32(23.9)$ & $17(25.4)$ & $49(24.4)$ & $76(28.3)$ \\
\hline Do not know & $7(10.4)$ & $15(11.2)$ & $8(11.9)$ & $23(11.4)$ & $30(11.2)$ \\
\hline
\end{tabular}

$36.3 \%$ of the nurses). Concerning knowledge on the side-effects of EC pills, the majority (90.3\%) mentioned nausea and vomiting (Table 3).

\section{Attitudes}

Most participants (95.9\%) stated that they supported the use of EC. Their responses on the age limit for issuing of EC were diverse; however, $41.0 \%$ said $>12$ years of age. They also gave diverse views on who should issue EC, with $23.1 \%$ saying doctors only, while $69.4 \%$ said either doctors, nurses or pharmacists. Nearly two-thirds (66.4\%) of participants disagreed with the idea that EC should be issued only with a doctor's prescription. More than three-quarters of participants (78.8\%) agreed with the notion that EC should be taught in the schools' curriculum.

Concerning the impact of EC, $79.5 \%$ said it could lead to highrisk sexual behaviour, $73.9 \%$ said it could lead to a high risk of transmission of HIV and $74.6 \%$ thought it could lead to non-use of other forms of contraception. Regarding the issuing of EC pills to a patient who came for a repeat dose after 1 week, $57.1 \%$ said they would not give a repeat dose. Those who said they would not issue a repeat gave different reasons for not doing so, with the majority (32.7\%) saying that they would instead advise the client on other forms of contraceptives. Some participants (16.8\%) felt it would be too soon to repeat the dose, while others said that they would not give it because the patient would be abusing it (19.5\%). On the issue of advance issuing of EC, most participants (75.7\%) said that they would not issue it in advance (Table 4).

\section{Practices}

Slightly more than half of participants (51.9\%) rarely saw patients requesting EC, $7.8 \%$ often had requests for EC and $40.3 \%$ had never had a request for EC. Regarding how frequently they taught patients about EC, $28.4 \%$ never taught, $48.1 \%$ rarely taught and $23.5 \%$ taught 
RESEARCH

Table 3. Knowledge on mechanism of action, effects on pregnancy and side-effects of EC pills (doctors, $N=67$; nurses, $N=201$ )

\begin{tabular}{|c|c|c|c|c|c|c|c|c|c|}
\hline & \multicolumn{3}{|c|}{ True, $n(\%)$} & \multicolumn{3}{|c|}{ False, $n(\%)$} & \multicolumn{3}{|c|}{ Do not know, $n$ (\%) } \\
\hline & Doctors & Nurses & Total & Doctors & Nurses & Total & Doctors & Nurses & Total \\
\hline \multicolumn{10}{|l|}{ Mechanism of action } \\
\hline Prevents ovulation & $27(40.3)$ & $79(39.3)$ & $106(39.6)$ & $36(53.7)$ & $97(48.3)$ & $133(49.6)$ & $4(6.0)$ & $25(12.4)$ & $29(10.8)$ \\
\hline Prevents implantation & $60(89.5)$ & $145(72.1)$ & $205(76.5)$ & $5(7.5)$ & $35(17.4)$ & $40(14.9)$ & $2(3.0)$ & $21(10.5)$ & $23(8.6)$ \\
\hline Causes abortion & $19(28.3)$ & $46(22.9)$ & $65(24.3)$ & $43(64.2)$ & $124(61.7)$ & $167(62.3)$ & $5(7.5)$ & $31(15.4)$ & $36(13.4)$ \\
\hline Prevents fertilisation & $37(55.2)$ & $136(67.7)$ & $173(64.6)$ & $19(28.4)$ & $33(16.4)$ & $52(19.4)$ & $11(16.4)$ & $32(15.9)$ & $43(16.0)$ \\
\hline $\begin{array}{l}\text { Causes malformations incompatible } \\
\text { with life }\end{array}$ & $4(6.0)$ & $19(9.5)$ & $23(8.6)$ & $50(74.6)$ & $103(51.2)$ & $153(57.1)$ & $13(19.4)$ & $79(39.3)$ & $92(34.3)$ \\
\hline \multicolumn{10}{|l|}{ Effect of EC pills on pregnant women } \\
\hline Spontaneous abortion & $39(58.2)$ & $75(37.3)$ & $114(42.5)$ & $23(34.3)$ & $95(47.3)$ & $118(44.0)$ & $5(7.5)$ & $31(15.4)$ & $36(13.5)$ \\
\hline Minor congenital abnormalities & $26(38.8)$ & $68(33.8)$ & $94(35.1)$ & $26(38.8)$ & $78(38.8)$ & $104(38.8)$ & $15(22.4)$ & $55(27.4)$ & $70(26.1)$ \\
\hline Major congenital abnormalities & $9(13.4)$ & $29(14.4)$ & $38(14.2)$ & $41(61.2)$ & $107(53.2)$ & $148(55.2)$ & $17(25.4)$ & $65(32.0)$ & $82(30.6)$ \\
\hline No effect on the mother and baby & $18(9.0)$ & $73(36.3)$ & $91(34)$ & $42(62.7)$ & $80(39.8)$ & $122(45.5)$ & $7(10.4)$ & $48(23.9)$ & $55(20.5)$ \\
\hline \multicolumn{10}{|l|}{ Common side-effects of EC pills } \\
\hline Nausea and vomiting & $64(95.5)$ & $178(88.5)$ & $242(90.3)$ & $1(1.5)$ & $10(5.0)$ & $11(4.1)$ & $2(3.0)$ & $13(6.5)$ & $15(5.6)$ \\
\hline Menorrhagia & $29(43.3)$ & $66(32.84)$ & $95(35.4)$ & $28(41.8)$ & $69(34.3)$ & $91(36.2)$ & $10(14.9)$ & $66(32.8)$ & $76(24.6)$ \\
\hline Delayed menses & $41(61.2)$ & $76(37.8)$ & $117(43.7)$ & $15(22.4)$ & $78(38.8)$ & $93(34.7)$ & $11(16.4)$ & $47(23.4)$ & $58(21.6)$ \\
\hline Amenorrhoea & $17(25.4)$ & $44(21.9)$ & $61(22.8)$ & $38(56.7)$ & $113(56.2)$ & $151(56.3)$ & $12(17.9)$ & $44(21.9)$ & $56(20.9)$ \\
\hline Diarrhoea & $17(25.4)$ & $54(26.9)$ & $71(26.5)$ & $30(44.8)$ & $86(42.8)$ & $116(43.3)$ & $20(29.8)$ & $61(30.3)$ & $101(30.2)$ \\
\hline
\end{tabular}

Table 4. Attitudes on EC (doctors, $N=67$; nurses, $N=201$ )

\begin{tabular}{|c|c|c|c|c|c|}
\hline & \multirow{2}{*}{$\begin{array}{l}\text { Doctors, } \\
n(\%) \\
\end{array}$} & \multicolumn{3}{|c|}{ Nurses, $\boldsymbol{n}(\%)$} & \multirow[b]{2}{*}{ Total, $n(\%)$} \\
\hline & & Hospital $(N=134)$ & Clinic $(N=67)$ & Total $(N=201)$ & \\
\hline \multicolumn{6}{|c|}{ Risky sexual behaviour } \\
\hline Agree & $51(76.1)$ & $110(82.1)$ & $52(77.6)$ & $162(80.6)$ & $213(79.5)$ \\
\hline Disagree & $16(23.9)$ & $24(17.9)$ & $15(22.4)$ & $39(19.4)$ & $55(20.5)$ \\
\hline \multicolumn{6}{|c|}{ High risk of transmission of HIV } \\
\hline Yes & $45(67.2)$ & $104(77.6)$ & $49(73.1)$ & $153(76.1)$ & 198 (73.9) \\
\hline No & $22(38.2)$ & $30(22.4)$ & $18(26.9)$ & $48(23.9)$ & $70(26.1)$ \\
\hline \multicolumn{6}{|c|}{ Non-use of other forms of contraception } \\
\hline Yes & $50(74.6)$ & $101(75.4)$ & $49(73.1)$ & $150(74.6)$ & $200(74.6)$ \\
\hline No & $17(25.4)$ & $33(24.6)$ & $18(26.9)$ & $51(25.4)$ & $68(25.4)$ \\
\hline \multicolumn{6}{|c|}{ Repeat dose of EC pills within 1 week } \\
\hline Yes & $28(41.8)$ & $56(41.8)$ & $31(46.3)$ & $87(43.3)$ & $115(42.9)$ \\
\hline No & $39(58.2)$ & $78(58.2)$ & $36(53.7)$ & $114(56.7)$ & $153(5.1)$ \\
\hline \multicolumn{6}{|c|}{ Advance prescription of EC } \\
\hline Yes & $18(26.9)$ & $28(20.9)$ & $19(28.4)$ & $47(23.4)$ & $65(24.3)$ \\
\hline No & $49(73.1)$ & $106(79.1)$ & $48(71.6)$ & $154(76.6)$ & $203(75.7)$ \\
\hline
\end{tabular}

Table 5. Practices regarding EC (doctors, $N=67$; nurses, $N=201$ )

\begin{tabular}{|c|c|c|c|c|c|}
\hline & \multirow{2}{*}{$\begin{array}{l}\text { Doctors, } \\
n(\%) \\
\end{array}$} & \multicolumn{3}{|c|}{ Nurses, $n(\%)$} & \multirow{2}{*}{$\begin{array}{l}\text { Total } \\
(N=268), \\
n(\%)\end{array}$} \\
\hline & & Hospital $(N=134)$ & Clinic $(N=67)$ & Total $(N=201)$ & \\
\hline \multicolumn{6}{|c|}{ Frequency of seeing patients requesting EC } \\
\hline Never & $30(44.8)$ & $67(50.0)$ & $11(16.4)$ & $78(38.8)$ & $108(40.3)$ \\
\hline Rarely & $32(47.8)$ & $62(46.3)$ & $45(67.2)$ & $107(53.2)$ & $139(51.9)$ \\
\hline Often & $5(7.4)$ & $5(3.7)$ & $11(16.4)$ & $16(8.0)$ & $21(7.8)$ \\
\hline \multicolumn{6}{|c|}{ Frequency of educating patients about EC } \\
\hline Never & $22(32.8)$ & $45(33.6)$ & $9(13.4)$ & $54(26.9)$ & $76(28.4)$ \\
\hline Rarely & $37(55.2)$ & $58(43.3)$ & $34(50.8)$ & $92(45.8)$ & $129(48.1)$ \\
\hline Often & $8(12.0)$ & $31(23.1)$ & $24(35.8)$ & $55(27.3)$ & $63(23.5)$ \\
\hline \multicolumn{6}{|c|}{ Frequency of issuing EC } \\
\hline Never & $34(50.7)$ & $90(67.0)$ & $15(22.4)$ & $105(52.2)$ & $139(51.9)$ \\
\hline Rarely & $29(43.3)$ & $40(30.0)$ & $45(67.2)$ & $85(42.3)$ & $114(42.5)$ \\
\hline Often & $4(6.0)$ & $4(3.0)$ & $7(10.4)$ & $11(5.5)$ & $15(5.6)$ \\
\hline
\end{tabular}


patients often. On the issue of issuing EC to patients, $51.9 \%$ never issue, $42.5 \%$ rarely issue and $5.6 \%$ issue EC often (Table 5).

\section{Discussion}

Although most participants were doctors and nurses working in one of the three public hospitals where they do not frequently encounter patients seeking EC, the level of awareness of the available methods of EC in the public sector in SA was high, particularly for the COC pill method (82.5\%), the POP (59.\%) and the Cu-IUCD (27.6\%). Overall awareness was high when compared with a similar survey of healthcare providers in Lagos, Nigeria, where $64.1 \%, 50.7 \%$ and $19.3 \%$ mentioned the COC, the POP and the $\mathrm{Cu}$-IUCD, respectively. ${ }^{[15]}$ In this study, awareness of the COC and POP methods was highest among the clinic nurses, at $88.1 \%$ and $73.1 \%$, respectively. Hospital nurses and doctors were slightly less aware of these methods but awareness of the use of the Cu-IUCD was highest among the doctors (65.7\%). In contrast, only $19.4 \%$ of hospital nurses and $6 \%$ of the clinic nurses were aware of the $\mathrm{Cu}-\mathrm{IUCD}$. When compared with an EC survey conducted in Turkey, where $35.3 \%$ of general practitioners (GPs) and $32.6 \%$ of nurses knew that the IUCD could be used for EC, the nurses' level of awareness of IUCD for EC was lower, while that of doctors was higher. ${ }^{[16]}$ However, when compared with a survey of family planning providers in Ghana, where only $8.3 \%$ of family planning providers were aware that the IUCD could be used as EC, ${ }^{[17]}$ their level of awareness was much higher. Two-thirds of the healthcare professionals could prescribe at least one EC and about half (54.3\%) knew the 72-hour time limit for EC pills as in the Nigerian survey, ${ }^{[15]}$ where knowledge of the indications of EC was high.

Knowledge of the mechanisms of action of EC pills was lacking as only $39.6 \%$ knew that they prevent ovulation, while the majority thought that they prevent implantation (76.5\%) and fertilisation (64.6\%). The results are similar to the survey in Turkey, where $87.1 \%$ of participants (96.1\% GPs v. $82 \%$ nurses and midwives) thought that the mechanism of action of EC was prevention of implantation. ${ }^{[16]}$ However, the knowledge was higher when compared with the survey in Ghana, where only $2.5 \%$ of the providers knew that EC pills prevent or delay ovulation. ${ }^{[17]}$ Knowledge on the side-effects and issuing of EC was particularly high. However, knowledge of how frequently it should be issued and the age restriction was low.

Most participants (95.9\%) agreed that it was okay to use EC. However, about three-quarters of the participants had a misperception that EC might lead to high-risk sexual behaviour (79.5\%), high risk of transmission of HIV (73.9\%) and non-use of other forms of contraception $(74.6 \%)$. These results were similar to those in the survey in Turkey, where $88.2 \%$ of GPs and $75.3 \%$ of nurses and midwives thought that if patients knew about EC, there would be a reduction in the use of condoms, and $76.4 \%$ thought that the use of EC could result in an increase in the rate of HIV and sexually transmitted infections. ${ }^{[16]}$ The majority (41\%) said that women should be offered EC from the age of 12 years. They gave diverse responses on who they thought should issue EC, with the majority preferring nurses (28.7\%). Most of the participants (66.4\%) disagreed with the suggestion that EC should only be issued with a doctor's prescription.

The majority of the healthcare professionals never or rarely saw patients seeking EC and never or rarely issued EC, unlike in the Nigerian survey, where $58 \%$ had prescribed EC. ${ }^{[15]}$ It is important to note that two-thirds of them work in a hospital setting where they rarely encounter these patients, but the clinic nurses, where most patients should present, also had similar results. Of concern is that they never or rarely educate their patients on EC.

\section{Conclusion}

Although most participants work in facilities where they do not encounter patients seeking EC, the level of awareness of ECs is high, but most health professionals lack accurate and detailed knowledge about the mechanisms of action of EC pills. Two-thirds of participants could prescribe at least one EC correctly and $\sim 50 \%$ knew the time limit of EC pills. The majority of participants had misperceptions on the impact of EC and the provision of EC service is poor, even among the health professionals who work in clinics. There is a great need to do in-service training of healthcare professionals to dispel their misperceptions and increase their knowledge, thereby changing their attitudes and practices on EC.

1. Singh S, Sedgh G, Hussain R. Unintended pregnancy: Worldwide levels, trends, and outcomes. Stud Fam Plann 2010;41(4):241-250. https://doi.org/10.1111/j.1728-4465.2010.00250.x

2. Hubacher D, Mavranezouli I, McGinn E. Unintended pregnancy in sub-Saharan Africa: Magnitude of the problem and potential role of contraceptive implants to alleviate it. Contraception 2008;78(1):7378. https://doi.org/10.1016/j.contraception.2008.03.002

3. Sedgh G, Henshaw S, Singh S, Åhman E, Shah IH. Induced abortion: Estimated rates and trends worldwide. Lancet 2007;370(9595):1338-1345. https://doi.org/10.1016/s0140-6736(07)61575-x

4. World Health Organization. Unsafe abortion: Global and regional estimates of the incidence of unsafe abortion and associated mortality in 2008. 6th ed. http://www.who.int/ reproductivehealth/ publications/unsafe_abortion/9789241501118/en (accessed 26 June 2013).

5. Shah I, Åhman E. Unsafe abortion in 2008: Global and regional levels and trends. Reprod Health Matters 2010;18(36):90-101. https://doi.org/10.1016/s0968-8080(10)36537-2

6. Pruitt SL, Mullen PD. Contraception or abortion? Inaccurate descriptions of emergency contraception in newspaper articles, 1992-2002. Contraception 2005;71(1):14-21. https://doi.org/10.1016/j. contraception.2004.07.012

7. Xu J, Cheng L. Awareness and usage of emergency contraception among teenagers seeking abortion: A Shanghai survey. Eur J Obstet Gynecol Reprod Biol 2008;141(2):143-146. https://doi.org/10.1016/j. ejogrb.2008.08.002

8. Miller LM. College student knowledge and attitudes toward emergency contraception. Contraception 2011;83(1):68-73. https://doi.org/10.1016/j.contraception.2010.06.005

9. Ertem G, Kalkim A, Topçu S. Knowledge of emergency contraception among married women in Izmir, Turkey. Int J Gynecol Obstet 2010;110(3):270-271. https://doi.org/10.1016/j.ijgo.2010.04.018

10. Smit J, McFadyen L, Beksinska M, et al. Emergency contraception in South Africa: Knowledge, attitudes, and use among public sector primary healthcare clients. Contraception 2001;64(6):333-337. https://doi.org/10.1016/s0010-7824(01)00272-4

11. Roberts C, Moodley J, Esterhuizen T. Emergency contraception: Knowledge and practices of tertiary students in Durban, South Africa. J Obstet Gynaecol 2004;24(4):441-445. https://doi.org/10.1080/0 1443610410001685619

12. Muia E, Ellertson C, Lukhando M, Elul B, Clark S, Olenja J. Emergency contraception in Nairobi, Kenya: Knowledge, attitudes and practices among policymakers, family planning providers and clients, and university students. Contraception 1999;60(4):223-232. https://doi.org/10.1016/s00107824(99)00089-x

13. Richman AR, Daley EM, Baldwin J, Kromrey J, O'Rourke K, Perrin K. The role of pharmacists and emergency contraception: Are pharmacists' perceptions of emergency contraception predictive of their dispensing practices? Contraception 2012;86(4):370-375. https://doi.org/10.1016/j. of their dispensing praction.2012.01.014

14. Lawrence RE, Rasinski KA, Yoon JD, Curlin FA. Obstetrician-gynecologist physicians' beliefs about emergency contraception: A national survey. Contraception 2010;82(4):324-330. https://doi. org/10.1016/j.contraception.2010.04.151

15. Ebuehi OM, Osaretin AT, Ebuehi VI. Health care providers' knowledge of attitudes toward and provision of emergency contraceptives in Lagos, Nigeria. Int Fam Plann Perspect 2006;32(2)89-93. https://doi.org/10.1363/3208906

16. Sevil U, Yanikkerem E, Hatipoglu S. A survey of knowledge, attitudes and practices relating to emergency contraception among health workers in Manisa, Turkey. Midwifery 2006;22(1):66-77. https://doi.org/10.1016/j.midw.2005.03.004

17. Creanga AA, Schwandt HM, Danso KA, Tsui AO. Knowledge about emergency contraception among family-planning providers in urban Ghana. Int J Gynecol Obstet 2011;114(1):64-68. https://doi. org/10.1016/j.ijgo.2011.01.024 